\title{
miR-365 overexpression promotes cell proliferation and invasion by targeting ADAMTS-1 in breast cancer
}

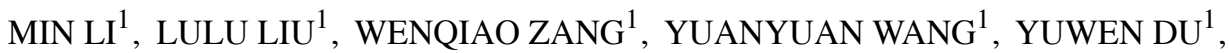 \\ XIAONAN CHEN ${ }^{1}$, PING $\mathrm{LI}^{2}$, JUAN $\mathrm{LI}^{2}$ and GUOQIANG ZHAO ${ }^{1}$ \\ ${ }^{1}$ College of Basic Medical Sciences, Zhengzhou University, Zhengzhou 450001; ${ }^{2}$ Department of Respiratory Medicine, \\ The First Affiliated Hospital of Zhengzhou University, Zhengzhou 450052, P.R. China
}

Received March 23, 2015; Accepted May 8, 2015

DOI: $10.3892 /$ ijo.2015.3015

\begin{abstract}
MicroRNAs (miRNAs) have important roles in the initiation and progression of human cancer, including breast cancer. We evaluated miR-365 expression in breast cancer tissues, and investigated its effects on cell growth, cell cycle, cell invasion, and expression of its target gene ADAMTS-1. miR-365 expression levels were analyzed in breast cancer tissues and adjacent normal tissues using qRT-PCR. CCK-8, cell cycle, and invasion assays were used to explore the role of miR-365 expression in breast cancer cells. We conducted luciferase reporter and western blot assays to test whether ADAMTS-1 is a direct target of miR-365. We found that miR-365 expression levels were significantly higher in breast cancer tissues compared with adjacent non-tumor tissues $(\mathrm{P}<0.05)$. These relatively high expression levels were significantly associated with advanced clinical stages $(\mathrm{P}<0.05)$. In breast cancer cell lines, transfection with miR-365 inhibitor suppressed proliferation and invasion, and resulted in cell cycle arrest. Subsequent experiments indicated that miR-365 bound the 3'-UTR of ADAMTS-1 and downregulated its expression. Our findings indicated that the inhibition of miR-365 reduced cell proliferation and cell invasion. Additionally, miR-365 may function as a novel oncogene in breast cancer through targeting ADAMTS-1. These findings provide insight into the mechanism of breast cancer pathogenesis.
\end{abstract}

\section{Introduction}

Breast cancer is a leading cause of cancer-related deaths in women worldwide (1). In 2005, microRNA (miRNA) deregulation was first described in breast cancer (2). Subsequently, a growing number of studies reported altered expression of miRNAs was connected with breast cancer (3). miRNAs are a class of small conserved non-coding RNAs that play a signifi-

Correspondence to: Professor Guoqiang Zhao, College of Basic Medical Sciences, Zhengzhou University, 100 Kexue Road, Zhengzhou 450001, P.R. China

E-mail: zhaogq@zzu.edu.cn

Key words: breast cancer, miR-365, cell cycle, invasion, ADAMTS-1 cant role in many physiological and pathological processes, including cell proliferation, angiogenesis, metastasis, and epigenetic changes (4-8). miRNAs can bind the 3'-UTRs of target mRNAs and thereby post-transcriptionally regulate gene expression via translational inhibition or target mRNA degradation (9-13). In a variety of tumor types, miRNA expression was different between tumor and normal tissues, as well as between metastatic and non-metastatic tumors $(14,15)$. Based on miRNA manipulations, the development of new therapies is urgently needed.

miR-365 is located on 16p13.12. A previous study confirmed that miR-365 was downregulated in colon cancer tissues, was involved in tumor progression and poor survival, and regulated cancer cell behavior by targeting cyclin D1 and Bcl-2 (16). miR-365 was also overexpressed both in cells and cutaneous squamous cell carcinoma tissues, suggesting that miR-365 may act as an oncogene both in vitro and in vivo (17). Moreover, recent studies indicated that miR-365 was upregulated in breast cancer (18). However, its function remains unclear.

In this study, we investigated miR-365 expression levels in breast cancer tissues, and evaluated its effect on cell growth, cell invasion, and cell cycle in breast cancer cells. Furthermore, we verified the target relationship between miR-365 and ADAMTS-1.

\section{Materials and methods}

Breast cancer specimens. Breast cancer specimens and adjacent normal breast tissues (64 cases) were obtained from the Tumor Hospital Affiliated to Zhengzhou University from July 2013 to September 2014. All samples were immediately snap-frozen in liquid nitrogen, and no patient had received chemotherapy or radiotherapy before surgery. Clinical data from these samples are listed in Table I. The Ethics Committee of Zhengzhou University approved this study, and samples were obtained with informed consent from all patients.

Cell culture. MDA-MB-231 and MCF-7 breast cancer cell lines were purchased from American Type Culture Collection (ATCC). Cells were cultured in DMEM (Gibco, USA) supplemented with $10 \%$ fetal bovine serum (FBS, Gibco), penicillin $(100 \mathrm{U} / \mathrm{ml})$, and streptomycin $(100 \mu \mathrm{g} / \mathrm{ml})$. Cells were maintained at $37^{\circ} \mathrm{C}$ in a humidified chamber with $5 \% \mathrm{CO}_{2}$. 
Table I. Clinicopathological characteristics and miR-365 and ADAMTS-1 expression levels in 64 breast cancer patients.

\begin{tabular}{|c|c|c|c|c|c|}
\hline \multirow[b]{2}{*}{ Clinicopathological factor } & \multirow[b]{2}{*}{$\mathrm{n}$} & \multicolumn{2}{|c|}{$\begin{array}{c}\operatorname{miR}-365 \\
\text { expression }\left(2^{-\Delta \Delta C t}\right)\end{array}$} & \multicolumn{2}{|c|}{$\begin{array}{l}\text { ADAMTS-1 mRNA } \\
\text { expression }\left(2^{-\Delta \Delta c t}\right) \\
\end{array}$} \\
\hline & & Mean \pm SD & P-value & Mean \pm SD & P-value \\
\hline \multicolumn{6}{|l|}{ Age (years) } \\
\hline$\leq 60$ & 40 & $2.801 \pm 1.031$ & \multirow[t]{2}{*}{0.373} & $0.463 \pm 0.363$ & \multirow[t]{2}{*}{0.159} \\
\hline$>60$ & 24 & $2.571 \pm 0.920$ & & $0.637 \pm 0.615$ & \\
\hline \multicolumn{6}{|l|}{ Lymph node metastasis } \\
\hline Positive & 30 & $2.899 \pm 0.909$ & \multirow[t]{2}{*}{0.161} & $0.476 \pm 0.367$ & \multirow[t]{2}{*}{0.414} \\
\hline Negative & 34 & $2.551 \pm 0.966$ & & $0.575 \pm 0.558$ & \\
\hline \multicolumn{6}{|l|}{ Tumor size $(\mathrm{cm})$} \\
\hline$\leq 4$ & 42 & $2.819 \pm 1.059$ & \multirow[t]{2}{*}{0.242} & $0.501 \pm 0.497$ & \multirow[t]{2}{*}{0.532} \\
\hline$>4$ & 22 & $2.513 \pm 0.827$ & & $0.581 \pm 0.441$ & \\
\hline \multicolumn{6}{|l|}{ TNM stage } \\
\hline I & 5 & $3.936 \pm 0.587$ & \multirow[t]{4}{*}{0.001} & $0.232 \pm 0.065$ & \multirow[t]{4}{*}{0.000} \\
\hline II & 28 & $2.941 \pm 0.825$ & & $0.294 \pm 0.152$ & \\
\hline III & 24 & $2.431 \pm 0.936$ & & $0.699 \pm 0.507$ & \\
\hline IV & 7 & $1.905 \pm 0.932$ & & $1.091 \pm 0.559$ & \\
\hline \multicolumn{6}{|l|}{ Estrogen receptor } \\
\hline Positive & 30 & $2.797 \pm 0.986$ & \multirow[t]{2}{*}{0.535} & $0.454 \pm 0.385$ & \multirow[t]{2}{*}{0.247} \\
\hline Negative & 34 & $2.641 \pm 1.001$ & & $0.593 \pm 0.542$ & \\
\hline \multicolumn{6}{|l|}{ Progesterone receptor } \\
\hline Positive & 28 & $2.786 \pm 1.021$ & \multirow[t]{2}{*}{0.611} & $0.477 \pm 0.338$ & \multirow[t]{2}{*}{0.455} \\
\hline Negative & 36 & $2.658 \pm 0.975$ & & $0.568 \pm 0.563$ & \\
\hline
\end{tabular}

$\mathrm{P}<0.05$ statistical significance.

$R N A$ extraction and $q R T-P C R$. Total RNA was isolated from tissues and cells using TRIzol reagent (Invitrogen, USA) according to the manufacturer's instructions. For quantitative detection of miR-365, qRT-PCR analyses were performed using the Two Step Stemaim-it miR qRT-PCR Quantitation kit (Novland, China). We quantified U6 small nuclear RNA (U6 snRNA) as an endogenous control to normalize miRNA levels. SYBR Premix Ex Taq ${ }^{\mathrm{TM}}$ (Takara, Japan) was used to quantify ADAMTS-1 mRNA expression, and GADPH served as an endogenous control. Each sample was performed in triplicate on the ABI 7500 Fast thermocycler. Relative expression levels were analyzed using the $2^{-\Delta \Delta \mathrm{Ct}}$ or $2^{-\Delta \mathrm{Ct}}$ method.

miRNA transfection. The miR-365 mimics, miR-365 inhibitor, and negative controls (NC) were synthesized by GenePharma (Shanghai, China), and were transfected into MDA-MB-231 and MCF-7 cells (at $100 \mathrm{nM}$ ) using Lipofectamine ${ }^{\mathrm{TM}} 2000$ (Invitrogen) according to the manufacturer's instructions. We assessed transfection efficiencies using qRT-PCR at 24 h posttransfection.

Cell growth assay. Twenty-four hours post-transfection, MDA-MB-231 and MCF-7 cells were seeded into 96-well plates (4,000 cells/well). Cell proliferation was assessed at 0, 24, 48, 72, and $96 \mathrm{~h}$ as follows: $10 \mu \mathrm{l}$ Cell Counting Kit-8 (CCK-8) solution (Dojindo, Japan) was added to each well, and the cells were incubated for an additional $3 \mathrm{~h}$ at $37^{\circ} \mathrm{C}$. The absorbance value of $\mathrm{OD}_{450}$ was measured daily and used to estimate the number of viable cells. Each experiment was repeated three times.

Cell cycle assay. We determined cell cycle distribution using flow cytometer analyses. Forty-eight hours after transfection, cells from each group were harvested by trypsinization, washed with cold PBS, and fixed overnight at $4^{\circ} \mathrm{C}$ in $70 \%$ ethanol. Next, cells were digested for $2-3 \mathrm{~h}$ at $37^{\circ} \mathrm{C}$ using RNase $(0.1 \mathrm{~g} / \mathrm{l})$. After propidium iodide (PI) staining in the dark for $30 \mathrm{~min}$ at $4^{\circ} \mathrm{C}$, cells were analyzed using a FACScan ${ }^{\circledR}$ flow cytometer (BD Biosciences, USA).

Transwell assay. Transfected MDA-MB-231 cells $\left(0.2 \mathrm{ml}, 2 \times 10^{5}\right.$ cells $/ \mathrm{ml}$ ) were seeded in the upper chamber of the transwell (Costar, USA). The lower chamber was filled with DMEM plus $10 \%$ FBS. Each group was performed in triplicate. Cells were incubated at $37^{\circ} \mathrm{C}$ in a humidified atmosphere containing $5 \% \mathrm{CO}_{2}$ for $24 \mathrm{~h}$. Following incubation, non-invading cells were removed from the upper surface of the membrane and the Matrigel. Cells on the bottom surface of the membrane were fixed with $4 \%$ paraformaldehyde for $10 \mathrm{~min}$ and stained with $0.1 \%$ crystal violet for $30 \mathrm{~min}$ at $37^{\circ} \mathrm{C}$. The number of invasive cells in three random fields was counted using an inverted microscope (x200 magnification). 

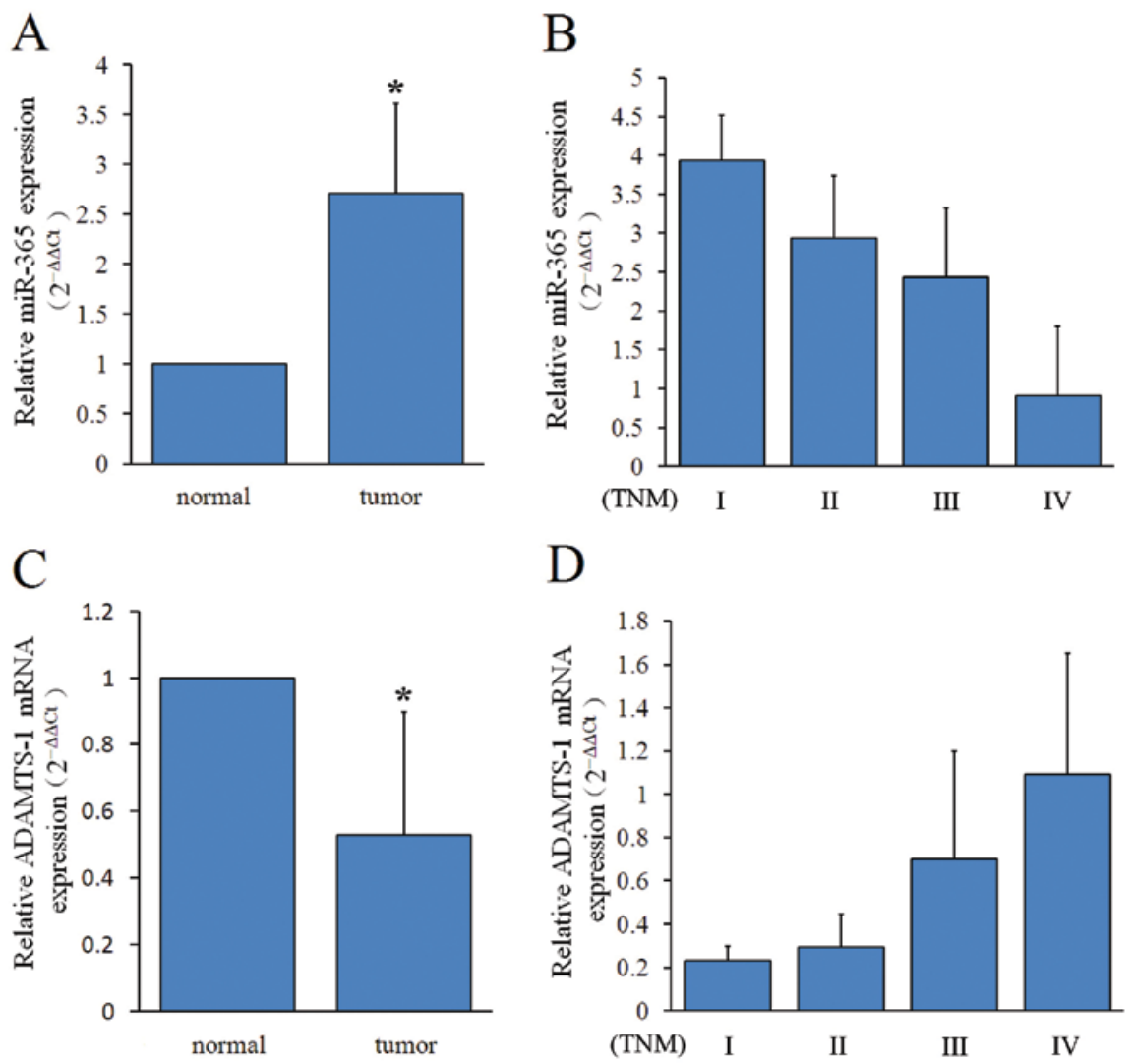

Figure 1. Expression levels of miR-365 and ADAMTS-1 mRNA in breast cancer tissues and adjacent normal tissues. (A) The relative expression of miR-365 was significantly higher in breast cancer tissues compared to adjacent normal tissues $(\mathrm{P}<0.05)$. (B) The expression levels of miR-365 were significantly different in different TNM stage $(\mathrm{P}<0.05)$. (C) Compared with adjacent normal tissues, the relative expression of ADAMTS-1 mRNA was significantly lower in breast cancer $(\mathrm{P}<0.05)$. (D) The expression levels of ADAMTS-1 mRNA stratified by TNM stage $(\mathrm{P}<0.05)$. The expression levels of miR-365 were analyzed by qRT-PCR, which were based on the algorithm $\left[\left(2^{-\Delta \Lambda C t}\right)\right]$.

Dual-luciferase assay. The 3'-UTR of ADAMTS-1, which contains a putative target region for miR-365, was PCR amplified from genomic DNA. The ADAMTS-1 3'-UTR mutant construct was generated by overlap extension PCR. Fragments were inserted between the XbaI and XhoI sites in the pmirGLO Dual-Luciferase miRNA Target Expression vector (Promega, USA) to generate the recombinant vectors pmirGLO-ADAMTS-1-wt and pmirGLO-ADAMTS-1-mut. Both insertions were verified by sequencing (Sangon, China). In MDA-MB-231 cells, co-transfection of the reporter vectors and miRNA (miR-365 mimics, miR-365 inhibitor or NC) was performed using Lipofectamine 2000. Twenty-four hours after transfection, luciferase and renilla signals were measured using the Dual Luciferase Reporter Assay kit (Promega) according to the manufacturer's protocol.

Western blotting. Total proteins were extracted using RIPA buffer according to the manufacturer's instructions. Lysates were centrifuged at $12,000 \mathrm{x}$ g for $30 \mathrm{~min}$ at $4^{\circ} \mathrm{C}$, and the supernatants were obtained. Protein concentrations were determined using a BCA Protein Assay kit (Beyotime, China). Equal amounts of total protein $(50 \mu \mathrm{g})$ were boiled for $5 \mathrm{~min}$, separated by SDS-PAGE, and transferred to PVDF membranes. After blocking for $1 \mathrm{~h}$ at room temperature with $5 \%$ non-fat dry milk, membranes were incubated at $4^{\circ} \mathrm{C}$ overnight with the primary antibodies (1:900 dilution, polyclonal rabbit anti-ADAMTS-1 and polyclonal rabbit anti-GAPDH, Santa Cruz, USA), followed by incubation with the horseradish peroxidase-linked secondary antibody (1:2,000 dilution, goat anti-rabbit IgG, Santa Cruz) for $1 \mathrm{~h}$ at $37^{\circ} \mathrm{C}$. All blots were visualized using an enhanced chemiluminescence (ECL) system (Amersham Pharmacia Biotech, NJ, USA).

Statistical analyses. Statistical analyses were performed using SPSS 17.0 software. All experiments were performed a minimum of three times, and results are expressed as the mean \pm standard deviation (SD). One-way analyses of variance (ANOVA) were used to compare differences between experimental groups. Differences were considered statistically significant at $\mathrm{P}$-values $<0.05$. Asterisk in the figures indicate the statistical significantce.

\section{Results}

miR-365 is upregulated and ADAMTS-1 is downregulated in breast cancer. To evaluate miR-365 expression in a cohort of breast cancer patient samples $(n=64)$, we used qRT-PCR. We found that miR-365 expression levels were significantly higher in breast cancer tissues than in adjacent non-tumor tissues $(\mathrm{P}<0.05$, Table I and Fig. 1A). Statistical analyses showed that miR-365 expression in breast cancer was associated with clinical stage $(\mathrm{P}<0.05$, Table 1 and Fig. $1 \mathrm{~B})$. There were no 

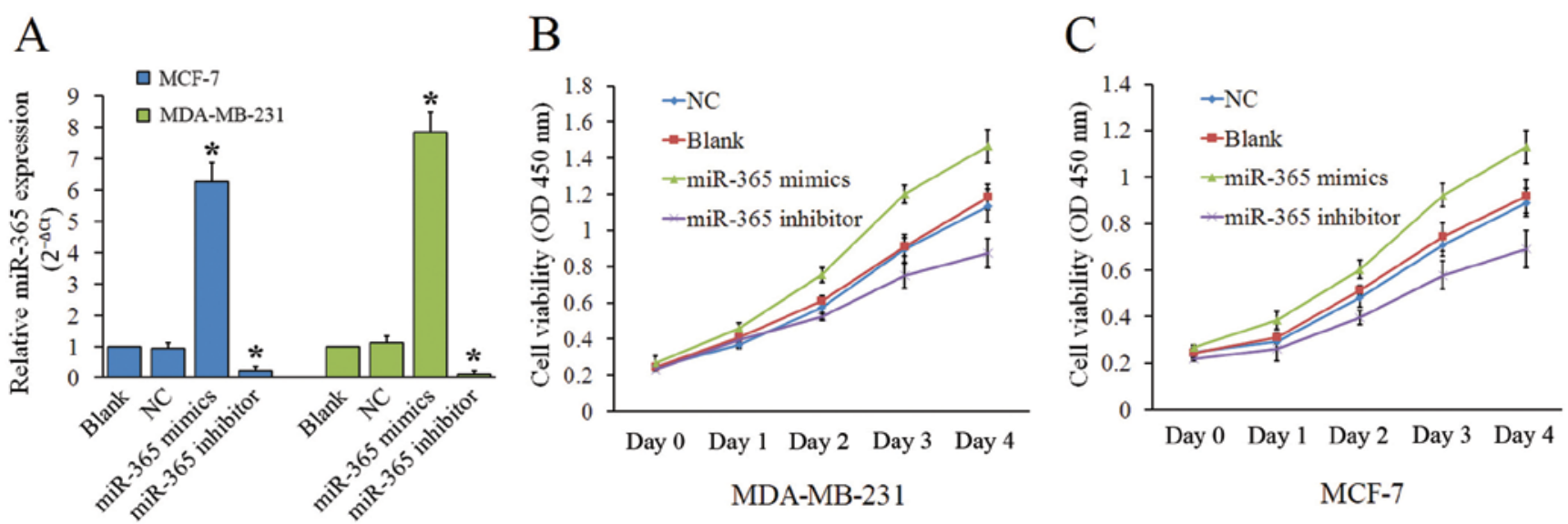

Figure 2. Effect of miR-365 on cell proliferation analyzed by CCK-8 assay. (A) Compared to Blank group, the relative miR-365 expression levels in miR-365 mimics, miR-365 inhibitor and NC group are shown in the histogram. The data were analyzed by qRT-PCR, which were based on the method $\left(2^{-\Delta \Delta C}\right.$ ). (B and C) In CCK-8 assay, the absorbance of cells markedly decreased in miR-365 inhibitor group, and increased in the group of miR-365 mimics compared to the control groups (NC and Blank group). NC, cells transfected with scrambled miR-365 negative control; Blank, non-transfected cells; miR-365 mimics, cells transfected with miR-365 mimics; miR-365 inhibitor, cells transfected with miR-365 inhibitor.
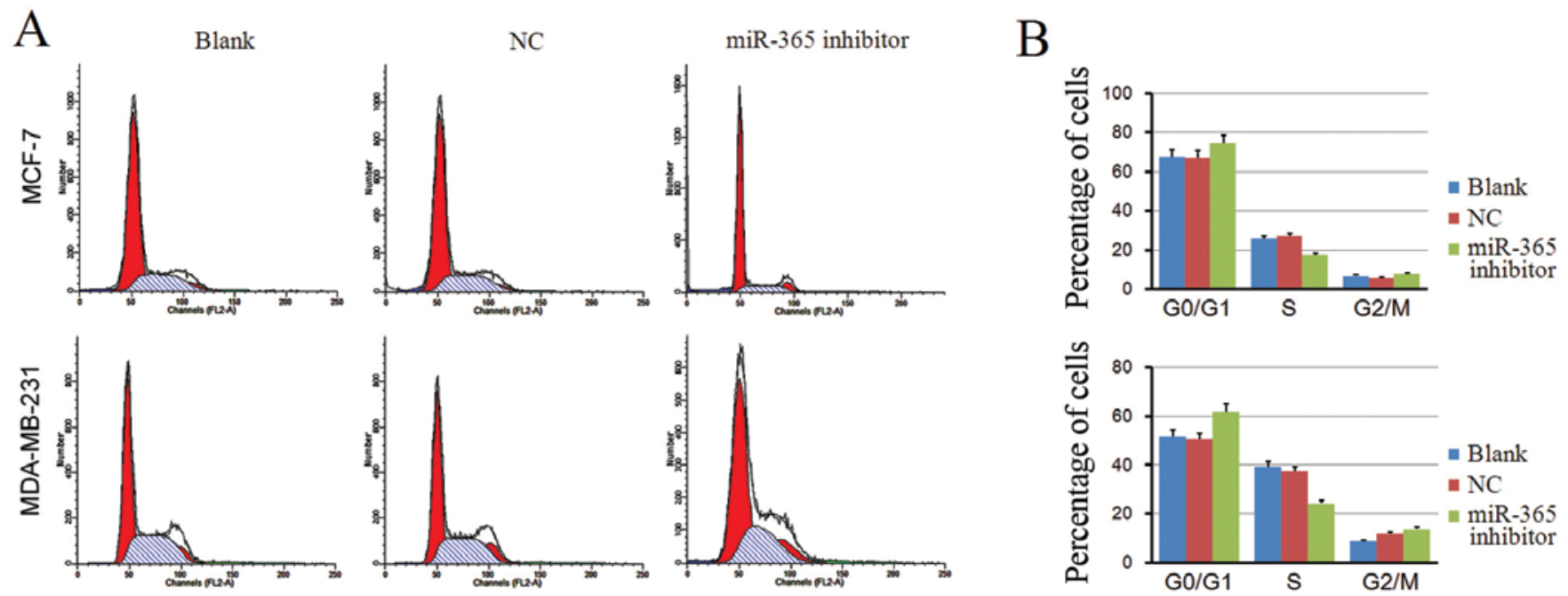

Figure 3. Effect of miR-365 downregulation on cell cycle progression in MDA-MB-231 and MCF-7 cells. (A) Cell cycle distribution was analyzed by flow cytometry. (B) The histogram show more cells in the G0/G1 phase and fewer cells in S phase following transiently transfected miR-365 inhibitor $(\mathrm{P}<0.05)$.

differences between miR-365 expression and age, tumor size, lymph node metastasis, or estrogen receptor and progesterone receptor positivity $(\mathrm{P}>0.05$, Table $\mathrm{I})$.

Using qRT-PCR assay, we found ADAMTS-1 mRNA expression in breast cancer varied, with the expression levels ranging from 0.09 to 2.68. The mean ADAMTS-1 expression value was significantly lower in breast cancer tissues than in adjacent non-tumor tissues $(\mathrm{P}<0.05$, Table $\mathrm{I}$ and Fig. $1 \mathrm{C})$. Increased ADAMTS-1 expression in breast cancer was associated with clinical stage $(\mathrm{P}<0.05$, Table I and Fig. 1D). However, we observed no statistically differences between ADAMTS-1 expression and age, tumor size, lymph node metastasis, or estrogen receptor and progesterone receptor positivity $(\mathrm{P}>0.05$, Table I).

miR-365 downregulation inhibits proliferation in vitro. We used qRT-PCR and found that miR-365 expression in cells transfected with miR-365 mimics was significantly higher than the Blank group or NC group. miR-365 expression levels in cells transfected with the miR-365 inhibitor were decreased compared to the Blank group or $\mathrm{NC}$ group ( $\mathrm{P}<0.05$, Fig. $2 \mathrm{~A})$. In CCK-8 assay, we measured $\mathrm{OD}_{450}$ values of cells transfected with NC, miR-365 mimics, and the miR-365 inhibitor. As shown in Fig. 2B and C, our data indicate that miR-365 downregulation reduced proliferation of MDA-MB-231 and MCF-7 cells.

The cell cycle was affected following miR-365 downregulation in vitro. Cell cycle arrest was successfully induced $48 \mathrm{~h}$ post-transfection (Fig. 3). Flow cytometry histograms show non-transfected cells and cells transfected with scrambled miR-365 or the miR-365 inhibitor (Fig. 3A). Cells transfected with miR-365 inhibitor had a significant increase in the percentage of $\mathrm{G} 0 / \mathrm{G} 1$ cells compared to other groups, 

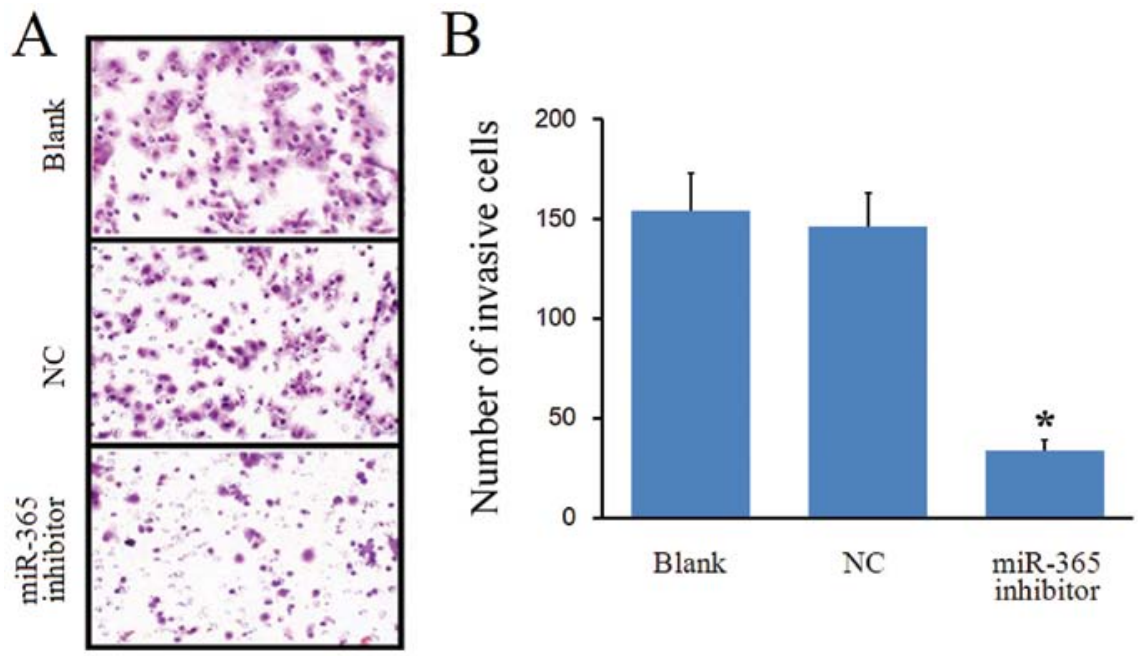

Figure 4. Downregulation of miR-365 inhibits cell invasion in vitro. (A) Transwell assay showed staining invasive cells in miR-365 inhibitor transfected group, NC transfected group and Blank group. (B) Histogram indicates the number of invasive cells in miR-365 inhibitor transfected group was significantly lower compared to other groups.

A

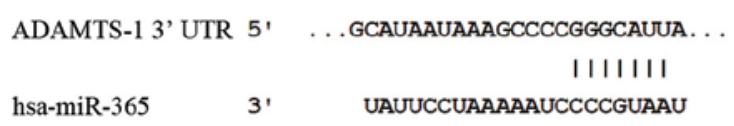

$\mathrm{B}$

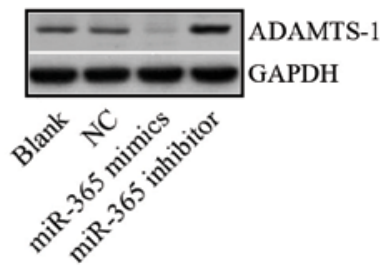

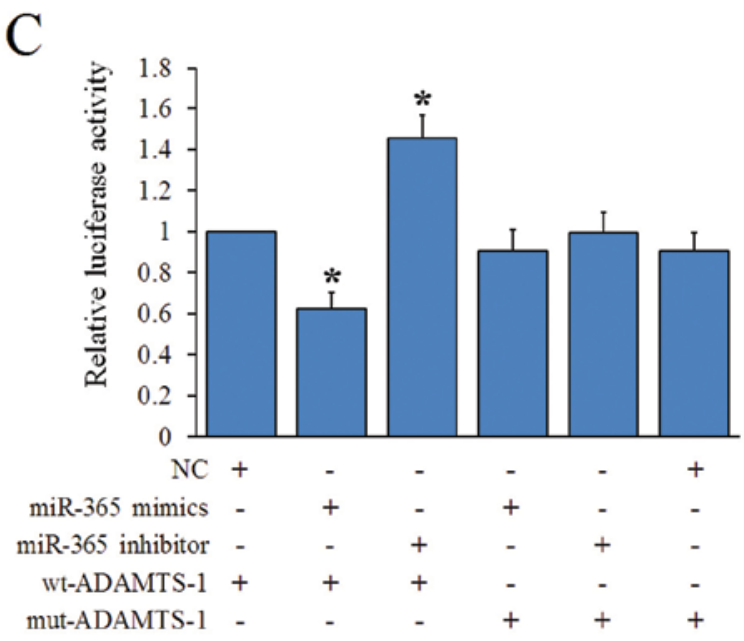

Figure 5. ADAMTS-1 is a direct target of miR-365. (A) The putative miR-365 binging site of ADAMTS-1 3'-UTR. (B) The expression of ADAMTS-1 was analyzed in miR-365 inhibitor, mimics, NC or Blank group. GAPDH was used as a reference. NC, cells transfected with scrambled miR-365 negative control; Blank, non-transfected cells; miR-365 mimics, cells transfected with miR-365 mimics; miR-365 inhibitor, cells transfected with miR-365 inhibitor. (C) Dualluciferase assay was performed to analyze the relative luciferase activity after transfection. wt-ADAMTS-1, pmirGLO-ADAMTS-1-wt; mut-ADAMTS-1, pmirGLO-ADAMTS-1-mut.
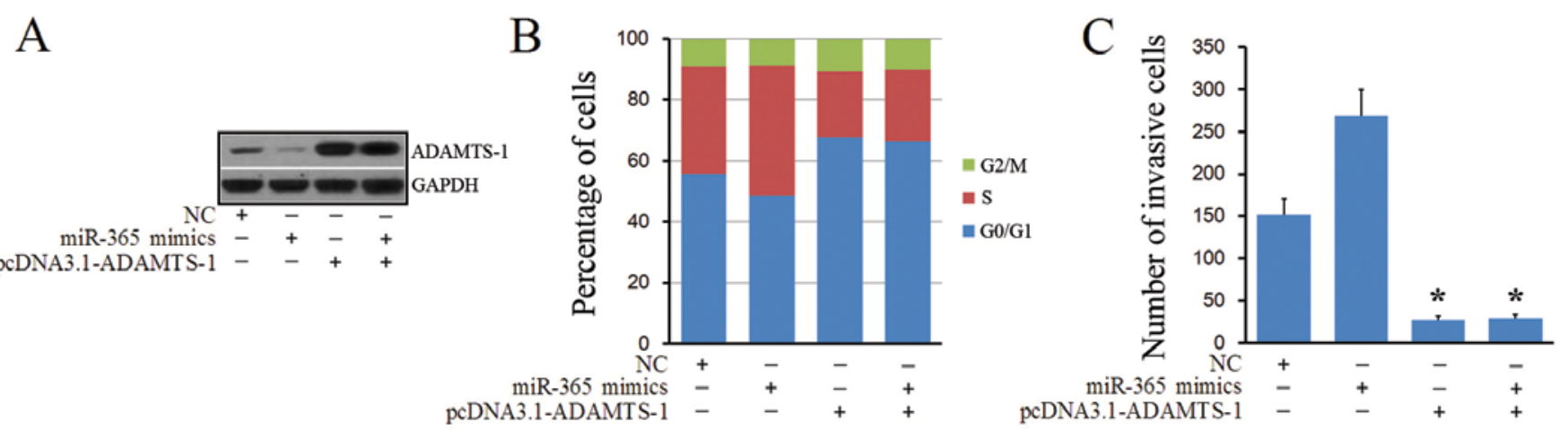

Figure 6. Expression of ADAMTS-1 restores the miR-365 pro-invasion and the effect on cell cycle function. (A) The ADAMTS-1 expression was increased when transfected with pcDNA3.1-ADAMTS-1 and miR-365 mimics. (B) The number of G0/G1 phase cells was increased, and S phase cells was decreased when transfected with pcDNA3.1-ADAMTS-1 and miR-365 mimics. (C) Co-transfected with miR-365 mimics and pcDNA3.1-ADAMTS-1 decreased the average number of invasive cells, abrogating the effect of miR-365 mimics on cell invasion. NC, cells transfected with scrambled miR-365 negative control; miR-365 mimics, cells transfected with miR-365 mimics; pcDNA3.1-ADAMTS-1, cells transfected with pcDNA3.1-ADAMTS-1. 
suggesting that miR-365 downregulation induced G0/G1 cell cycle arrest $(\mathrm{P}<0.05$, Fig. $3 \mathrm{~B})$. These results suggest that miR-365 downregulation inhibits cell cycle progression in MDA-MB-231 and MCF-7 cells.

miR-365 downregulation inhibits cell invasion in vitro. We used transwell assay to investigate the role of miR-365 in regulating invasion. As shown in Fig. 4, significantly fewer cells invaded the Matrigel in the miR-365 inhibitor group compared to the Blank and NC groups $(\mathrm{P}<0.05)$. However, no significant differences in the number of cells that invaded the Matrigel were observed between the NC group and Blank group ( $\mathrm{P}>0.05)$. These results indicate that miR-365 downregulation decreased the invasive capacity of MDA-MB-231 cells.

ADAMTS- 1 is a direct target of $m i R-365$. Next, we investigated potential targets of miR-365 using prediction algorithms (TargetScan, PicTar, and miRanda). Bioinformatics analyses predicted the ADAMTS-1 3'-UTR contained miR-365 binding sites (Fig. 5A). We analyzed ADAMTS-1 expression levels using western blotting and found that ADAMTS-1 expression was significantly lower in MDA-MB-231 cells following transfection with the miR-365 mimics. Moreover, ADAMTS-1 expression was significantly higher in cells transfected with the miR-365 inhibitor (Fig. 5B). To examine the target relationship, we constructed two reporter plasmids, pmirGLO-ADAMTS-1-wt and pmirGLO-ADAMTS-1-mut. These vectors were transfected into MDA-MB-231 cells with NC, miR-365 mimics, or the miR-365 inhibitor. We found that the luciferase activity was significantly reduced when the miR-365 mimic was co-transfected with the wt-ADAMTS-1 reporter plasmid. In contrast, the miR-365 inhibitor significantly promoted wt-ADAMTS-1 reporter plasmid luciferase activity (Fig. 5C). These data indicate that miR-365 regulated ADAMTS-1 expression by directly targeting the 3'-UTR of ADAMTS-1.

ADAMTS-1 expression restores the pro-invasion and cell cycle function of $m i R-365$. We constructed an expression vector (pcDNA3.1-ADAMTS-1) that exogenously expressed ADAMTS-1 lacking the 3'-UTR to further demonstrate the target relationship. Western blot analyses showed that co-transfection of miR-365 mimics and pcDNA3.1-ADAMTS-1 increased ADAMTS-1 expression as well as restored the function of the miR-365 mimics in regulating ADAMTS-1 expression (Fig. 6A). We also analyzed MDA-MB-231 cells co-transfected with miR-365 mimics and pcDNA3.1-ADAMTS-1 using flow cytometry and found that the population of cells in the G0/G1 phase increased, and the number of cells in the S phase decreased (Fig. 6B). Transwell assay revealed that the invasion accelerating effect of miR-365 was reversed by transfection with pcDNA3.1-ADAMTS-1 (Fig. 6C). Taken together, these findings further suggested that miR-365 regulated ADAMTS-1 expression through binding to its 3'-UTR.

\section{Discussion}

An increasing number of studies have revealed that dysregulation of specific miRNAs, which function as tumor suppressor or oncogenes, control breast cancer formation and progression and are found in tumor biopsies and body fluids (19-21). mir-15a has recently been found to participate in breast cancer progression. In vitro, miR-15a plays a role in potentiating apoptosis, suppressing proliferation, and mediating cell cycle arrest (22). It was recently found that miR-30c is dysregulated in breast cancer and its elevated expression correlated with poor patient survival. Moreover, miR-30c promotes the invasive phenotype of MDA-MB-231 cells (23). It has been reported that miR-10b upregulation is associated with brain metastases of breast cancer, suggesting that miR-10b can serve as a therapeutic target for anti-metastasis therapy (24). MiR-148a and miR-133a have been identified as biomarkers for breast cancer detection using a three-stage microRNA analysis (25). Furthermore, recent research found that miRNA-342-3p regulated sensitivity to the chemotherapy drugs paclitaxel and cisplatin in a breast cancer cell line (26). Based on microarray analysis data, miR-365 is highly expressed (18). However, the effect of miR-365 on cell proliferation, cell cycle, and cell invasion in breast cancer remained unknown. Here, we investigated the mechanisms of the oncogene miR-365, and performed luciferase reporter, western blotting, and restore assays to identify whether ADAMTS-1 is a direct target of miR-365.

In this study, we found that miR-365 expression is significantly higher in breast cancer tissues than normal adjacent tissues. In addition, elevated miR-365 expression was associated with clinical stage. These results suggest that upregulation of miR-365 may be related to breast cancer development. Moreover, we found that miR-365 suppression significantly restricted cell proliferation and cell invasion, as well as induced G0/G1 cell cycle arrest in vitro. These data indicate that miR-365 may function as an oncogene to promote cell proliferation by mediating G0/G1 cell cycle arrest.

ADAMTS-1 is an active multifunctional metalloproteinase that participates in a variety of carcinomas (27-30). However, the role of this enzyme in cancer development remains controversial. In 1999, Kuno et al showed that ADAMTS-1 is associated with the extracellular matrix, which may play a role in the inflammatory process (31). When overexpressed, catalytically-active ADAMTS-1 increases tumor growth rates and recruits fibroblastic cells, thus inducing a stromal reaction in vivo (32). In addition, increased ADAMTS-1 expression has been reported in pancreatic tumors with metastatic phenotypes (33). Low ADAMTS-1 expression was observed in non-smallcell lung cancer, and its dysregulation correlated with the development and progression of lung carcinoma (30). Recent studies revealed that ADAMTS-1 expression was decreased in human breast cancers, and ADAMTS-1 knockdown accelerated cell migration, invasion, and formation of invadopodia (34). Consistent with previous reports, we found ADAMTS-1 was downregulated in breast cancer. Based on our bioinformatics search of several online databases, we determined that ADAMTS-1 mRNA contained miR-365 binding sites. We found that miR-365 inhibited ADAMTS-1 expression in breast cancer cells. Using luciferase reporter and restore assays, we further confirmed that ADAMTS-1 is directly regulated by miR-365. Therefore, we propose that miR-365 functions by regulating ADAMTS-1 expression.

In conclusion, our study suggests that upregulated miR-365 negatively regulates ADAMTS-1 expression by targeting its 3'-UTR. We also found that miR-365 contributes to regula- 
tion of cell proliferation, invasion, and the cell cycle in breast cancer cells. Therefore, inhibition of miR-365 might be a potential therapeutic strategy for breast cancer.

\section{Acknowledgements}

The authors are grateful to all the staff at the study centre who contributed to this study. This study was supported by the National Natural Science Foundation of China (81272188; 81301726)

\section{References}

1. Jemal A, Bray F, Center MM, Ferlay J, Ward E and Forman D: Global cancer statistics. CA Cancer J Clin 61: 69-90, 2011.

2. Iorio MV, Ferracin M, Liu CG, Veronese A, Spizzo R, Sabbioni S, Magri E, Pedriali M, Fabbri M, Campiglio M, et al: MicroRNA gene expression deregulation in human breast cancer. Cancer Res 65: 7065-7070, 2005.

3. O'Day E and Lal A: MicroRNAs and their target gene networks in breast cancer. Breast Cancer Res 12: 201, 2010.

4. Lee RC, Feinbaum RL and Ambros V: The C. elegans heterochronic gene lin-4 encodes small RNAs with antisense complementarity to lin-14. Cell 75: 843-854, 1993.

5. Brennecke $J$ and Cohen SM: Towards a complete description of the microRNA complement of animal genomes. Genome Biol 4: $228,2003$.

6. Plummer PN, Freeman R, Taft RJ, Vider J, Sax M, Umer BA, Gao D, Johns C, Mattick JS, Wilton SD, et al: MicroRNAs regulate tumor angiogenesis modulated by endothelial progenitor cells. Cancer Res 73: 341-352, 2013.

7. Li Q, Zhu F and Chen P: miR-7 and miR-218 epigenetically control tumor suppressor genes RASSF1A and Claudin-6 by targeting Hox B3 in breast cancer. Biochem Biophys Res Commun 424: 28-33, 2012

8. Markou A, Yousef GM, Stathopoulos E, Georgoulias V and Lianidou E: Prognostic significance of metastasis-related microRNAs in early breast cancer patients with a long follow-up. Clin Chem 60: 197-205, 2014.

9. Bartel DP: MicroRNAs: Genomics, biogenesis, mechanism, and function. Cell 116: 281-297, 2004.

10. Meister G, Landthaler M, Dorsett Y and Tuschl T: Sequencespecific inhibition of microRNA- and siRNA-induced RNA silencing. RNA 10: 544-550, 2004.

11. Krol J, Loedige I and Filipowicz W: The widespread regulation of microRNA biogenesis, function and decay. Nat Rev Genet 11: 597-610, 2010.

12. Bartel DP: MicroRNAs: Target recognition and regulatory functions. Cell 136: 215-233, 2009.

13. Fabian MR, Sonenberg N and Filipowicz W: Regulation of mRNA translation and stability by microRNAs. Annu Rev Biochem 79: 351-379, 2010.

14. Sachdeva M and Mo YY: MicroRNA-145 suppresses cell invasion and metastasis by directly targeting mucin 1 . Cancer Res 70: 378-387, 2010.

15. Ma L, Teruya-Feldstein $\mathrm{J}$ and Weinberg RA: Tumour invasion and metastasis initiated by microRNA-10b in breast cancer. Nature 449: 682-688, 2007.

16. Nie J, Liu L, Zheng W, Chen L, Wu X, Xu Y, Du X and Han W: microRNA-365, down-regulated in colon cancer, inhibits cell cycle progression and promotes apoptosis of colon cancer cells by probably targeting Cyclin D1 and Bcl-2. Carcinogenesis 33: 220-225, 2012

17. Zhou M, Liu W, Ma S, Cao H, Peng X, Guo L, Zhou X, Zheng L, Guo L, Wan M, et al: A novel onco-miR-365 induces cutaneous squamous cell carcinoma. Carcinogenesis 34: 1653-1659, 2013.
18. Yan LX, Huang XF, Shao Q, Huang MY, Deng L, Wu QL, Zeng YX and Shao JY: MicroRNA miR-21 overexpression in human breast cancer is associated with advanced clinical stage, lymph node metastasis and patient poor prognosis. RNA 14: 2348-2360, 2008.

19. Shah NR and Chen H: MicroRNAs in pathogenesis of breast cancer: Implications in diagnosis and treatment. World J Clin Oncol 5: 48-60, 2014.

20. Blondal T, Jensby Nielsen S, Baker A, Andreasen D, Mouritzen P, Wrang Teilum $M$ and Dahlsveen IK: Assessing sample and miRNA profile quality in serum and plasma or other biofluids. Methods 59: S1-S6, 2013.

21. Jiang Q, Wang Y, Hao Y, Juan L, Teng M, Zhang X, Li M, Wang G and Liu Y: miR2Disease: A manually curated database for microRNA deregulation in human disease. Nucleic Acids Res 37 (Database): D98-D104, 2009.

22. Li P, Xie XB, Chen Q, Pang GL, Luo W, Tu JC, Zheng F, Liu SM, Han L, Zhang JK, et al: MiRNA-15a mediates cell cycle arrest and potentiates apoptosis in breast cancer cells by targeting synuclein- $\gamma$. Asian Pac J Cancer Prev 15: 6949-6954, 2014.

23. Dobson JR, Taipaleenmäki H, Hu YJ, Hong D, van Wijnen AJ, Stein JL, Stein GS, Lian JB and Pratap J: hsa-miR-30c promotes the invasive phenotype of metastatic breast cancer cells by targeting NOV/CCN3. Cancer Cell Int 14: 73, 2014.

24. Ahmad A, Sethi S, Chen W, Ali-Fehmi R, Mittal S and Sarkar FH: Up-regulation of microRNA-10b is associated with the development of breast cancer brain metastasis. Am J Transl Res 6: 384-390, 2014

25. Shen J, Hu Q, Schrauder M, Yan L, Wang D, Medico L, Guo Y, Yao S, Zhu Q, Liu B, et al: Circulating miR-148b and miR-133a as biomarkers for breast cancer detection. Oncotarget 5: 5284-5294, 2014.

26. Ma T, Zhang J, Wu J and Tang J: Effect of miR-342-3p on chemotherapy sensitivity in triple-negative breast cancer. Zhong Nan Da Xue Xue Bao Yi Xue Ban 39: 488-495, 2014 (In Chinese).

27. Llamazares M, Obaya AJ, Moncada-Pazos A, Heljasvaara R, Espada J, López-Otín C and Cal S: The ADAMTS12 metalloproteinase exhibits anti-tumorigenic properties through modulation of the Ras-dependent ERK signalling pathway. J Cell Sci 120: 3544-3552, 2007

28. Porter S, Scott SD, Sassoon EM, Williams MR, Jones JL, Girling AC, Ball RY and Edwards DR: Dysregulated expression of adamalysin-thrombospondin genes in human breast carcinoma. Clin Cancer Res 10: 2429-2440, 2004.

29. Porter S, Span PN, Sweep FC, Tjan-Heijnen VC, Pennington CJ, Pedersen TX, Johnsen M, Lund LR, Rømer J and Edwards DR: ADAMTS8 and ADAMTS15 expression predicts survival in human breast carcinoma. Int J Cancer 118: 1241-1247, 2006.

30. Rocks N, Paulissen G, Quesada Calvo F, Polette M, Gueders M, Munaut C, Foidart JM, Noel A, Birembaut P and Cataldo D: Expression of a disintegrin and metalloprotease (ADAM and ADAMTS) enzymes in human non-small-cell lung carcinomas (NSCLC). Br J Cancer 94: 724-730, 2006

31. Kuno K, Terashima Y and Matsushima K: ADAMTS-1 is an active metalloproteinase associated with the extracellular matrix. J Biol Chem 274: 18821-18826, 1999.

32. Rocks N, Paulissen G, Quesada-Calvo F, Munaut C, Gonzalez ML, Gueders M, Hacha J, Gilles C, Foidart JM, Noel A, et al: ADAMTS-1 metalloproteinase promotes tumor development through the induction of a stromal reaction in vivo. Cancer Res 68: 9541-9550, 2008

33. Masui T, Hosotani R, Tsuji S, Miyamoto Y, Yasuda S, Ida J, Nakajima S, Kawaguchi M, Kobayashi H, Koizumi M, et al: Expression of METH-1 and METH-2 in pancreatic cancer. Clin Cancer Res 7: 3437-3443, 2001

34. Freitas VM, do Amaral JB, Silva TA, Santos ES, Mangone FR, Pinheiro JJ, Jaeger RG, Nagai MA and Machado-Santelli GM: Decreased expression of ADAMTS-1 in human breast tumors stimulates migration and invasion. Mol Cancer 12: 2, 2013. 